\title{
Environmental performance of blue foods
}

https://doi.org/10.1038/s41586-021-03889-2

Received: 20 January 2021

Accepted: 9 August 2021

Published online: 15 September 2021

Check for updates

\author{
Jessica A. Gephart ${ }^{1,20 凶}$, Patrik J. G. Henriksson ${ }^{2,3,4,20}$, Robert W. R. Parker ${ }^{5,6,20}$, \\ Alon Shepon ${ }^{7,8,9,20}$, Kelvin D. Gorospe $^{1}, K_{\text {Kristina Bergman }}{ }^{10}$, Gidon Eshel ${ }^{11}$, \\ Christopher D. Golden ${ }^{9,12,13}$, Benjamin S. Halpern ${ }^{14,15}$, Sara Hornborg ${ }^{10}$, Malin Jonell ${ }^{2,4,16}$, \\ Marc Metian ${ }^{17}$, Kathleen Mifflin ${ }^{5}$, Richard Newton ${ }^{18}$, Peter Tyedmers ${ }^{5}$, Wenbo Zhang ${ }^{19}$, \\ Friederike Ziegler ${ }^{10}$ \& Max Troell $^{2,4}$
}

\begin{abstract}
Fish and other aquatic foods (blue foods) present an opportunity for more sustainable diets ${ }^{1,2}$. Yet comprehensive comparison has been limited due to sparse inclusion of blue foods in environmental impact studies ${ }^{3,4}$ relative to the vast diversity of production ${ }^{5}$. Here we provide standardized estimates of greenhouse gas, nitrogen, phosphorus, freshwater and land stressors for species groups covering nearly three quarters of global production. We find that across all blue foods, farmed bivalves and seaweeds generate the lowest stressors. Capture fisheries predominantly generate greenhouse gas emissions, with small pelagic fishes generating lower emissions than all fed aquaculture, but flatfish and crustaceans generating the highest. Among farmed finfish and crustaceans, silver and bighead carps have the lowest greenhouse gas, nitrogen and phosphorus emissions, but highest water use, while farmed salmon and trout use the least land and water. Finally, we model intervention scenarios and find improving feed conversion ratios reduces stressors across all fed groups, increasing fish yield reduces land and water use by up to half, and optimizing gears reduces capture fishery emissions by more than half for some groups. Collectively, our analysis identifies high-performing blue foods, highlights opportunities to improve environmental performance, advances data-poor environmental assessments, and informs sustainable diets.
\end{abstract}

The food system is a major driver of environmental change, emitting a quarter of all greenhouse gas (GHG) emissions, occupying half of all ice-free land, and responsible for three quarters of global consumptive water use and eutrophication ${ }^{3,6}$. Yet, it still fails to meet global nutrition needs ${ }^{7}$, with 820 million people lacking sufficient food $^{8}$ and with one in three people globally overweight or obese ${ }^{9}$. As a critical source of nutrition $^{8,10}$ generating relatively low average environmental pressures ${ }^{1,2,11,12}$, blue foods present an opportunity to improve nutrition with lower environmental burdens, in line with the Sustainable Development Goals to improve nutrition (Goal 2), ensure sustainable consumption and production (Goal 12), and sustainably use marine resources (Goal 14).

Bluefoods, however, are underrepresented in food system environmental assessments ${ }^{13}$ and the stressors considered are limited ${ }^{4}$ such that we have some understanding of GHG emissions ${ }^{14,15}$, but less of others such as land or freshwater use $\mathrm{s}^{16}$. Where blue foods are included, they are typically represented by only one or a few broad categories (see, for example, refs. ${ }^{3,17,18}$ ), masking the vast diversity within blue food production. Finally, estimates combining results of published life cycle assessments undertaken for different purposes, and consequently using incompatible methodologies $^{19,20}$, cannot be compared reliably. It is therefore critical to examine the environmental performance across the diversity of blue foods in a robust, methodologically consistent manner to serve as a benchmark within the rapidly evolving sector as blue food demand increases ${ }^{21}$, production shifts toward aquaculture and production technologies advance.

Here, we provide standardized estimates of GHG emissions, consumptive freshwater use (water use), terrestrial land occupation (land use), and nitrogen $(\mathrm{N})$ and phosphorus $(\mathrm{P})$ emissions for blue foods, reported per tonne of edible weight. We identify a set of key life cycle inventory data (that is, material and energy input, and farm-level performance data) from published studies and datasets to which a harmonized methodology is applied. We draw on studies that collectively report data from over 1,690 farms and 1,000 unique fishery records around the world. The 23 species groups represented in our results cover over $70 \%$ of global blue food production. We then discuss environmental impacts not covered by the standard stressors, most notably biodiversity loss. Finally, we leverage our model to identify and quantify improvement

${ }^{1}$ Department of Environmental Science, American University, Washington, DC, USA. ${ }^{2}$ Stockholm Resilience Centre, Stockholm, Sweden. ${ }^{3}$ WorldFish, Penang, Malaysia. ${ }^{4}$ Beijer Institute of Ecological Economics, The Royal Swedish Academy of Sciences, Stockholm, Sweden. ${ }^{5}$ School for Resource and Environmental Studies, Dalhousie University, Halifax, Nova Scotia, Canada. ${ }^{6}$ Aquaculture Stewardship Council, Utrecht, the Netherlands. ${ }^{7}$ Department of Environmental Studies, The Porter School of the Environment and Earth Sciences, Tel Aviv University, Tel Aviv, Israel. ${ }^{8}$ The Steinhardt Museum of Natural History, Tel Aviv University, Tel Aviv, Israel. ${ }^{9}$ Department of Nutrition, Harvard T. H. Chan School of Public Health, Boston, MA, USA. ${ }^{10}$ Department of Agriculture and Food, RISE Research Institutes of Sweden, Göteborg, Sweden. "'Department of Environmental Science, Bard College, Annandale-on-Hudson, NY, USA. ${ }^{12}$ Department of Environmental Health, Harvard T. H. Chan School of Public Health, Boston, MA, USA. ${ }^{13}$ Department of Global Health and Population, Harvard T. H. Chan School of Public Health, Boston, MA, USA. ${ }^{14}$ National Center for Ecological Analysis and Synthesis, University of California, Santa Barbara, CA, USA. ${ }^{15}$ Bren School of Environmental Science and Management, University of California, Santa Barbara, CA, USA. ${ }^{16} \mathrm{Global}$ Economic Dynamics and the Biosphere, The Royal Swedish Academy of Sciences, Stockholm, Sweden. ${ }^{17}$ International Atomic Energy AgencyEnvironment Laboratories (IAEA-EL), Radioecology Laboratory, Principality of Monaco, Monaco. ${ }^{18}$ Institute of Aquaculture, University of Stirling, Stirling, UK. ${ }^{19} \mathrm{College}$ of Fisheries and Life Science, Shanghai Ocean University, Shanghai, China. ${ }^{20}$ These authors contributed equally: Jessica A. Gephart, Patrik J. G. Henriksson, Robert W. R. Parker, Alon Shepon. ${ }^{\bowtie}$-mail: jgephart@ american.edu 

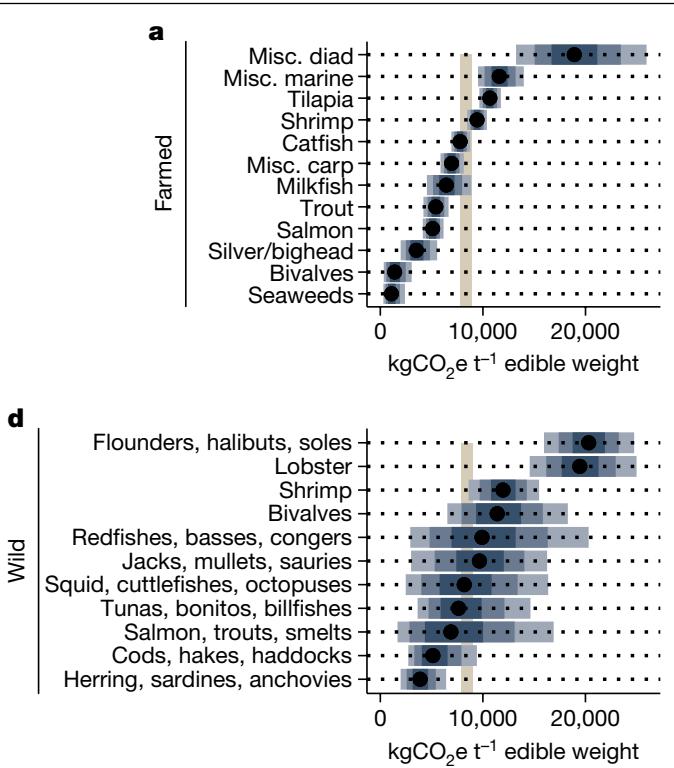

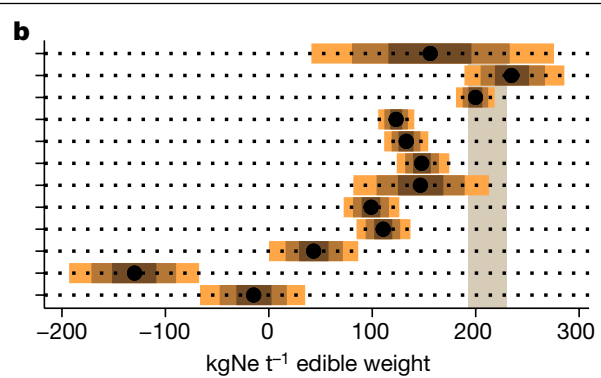

e

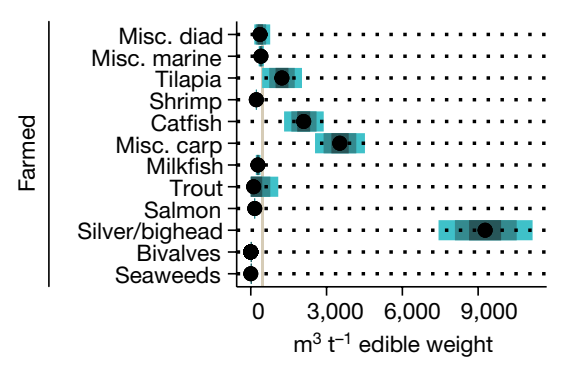

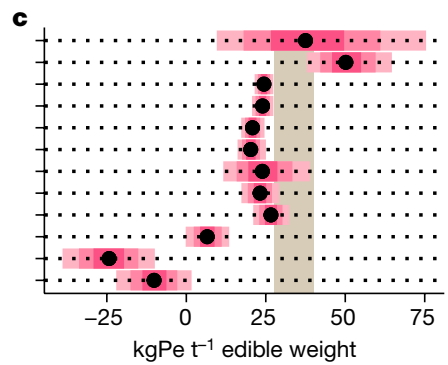

f

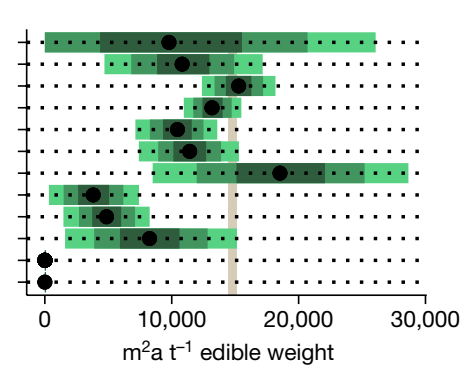

Fig. 1 | Stressor posterior distributions. a, Aquaculture $\mathrm{GHG}$ emissions $\left(\mathrm{kgCO}_{2} \mathrm{e} \mathrm{t}^{-1}\right) \cdot \mathbf{b}$, Aquaculture $\mathrm{N}\left(\mathrm{kgNe} \mathrm{t}^{-1}\right)$. c, Aquaculture P $\left(\mathrm{kgPe} \mathrm{t}^{-1}\right)$. d, Capture GHG emissions $\left(\mathrm{kgCO}_{2} \mathrm{e} \mathrm{t}^{-1}\right) \mathbf{e}$, Aquaculture Water use $\left(\mathrm{m}^{3} \mathrm{t}^{-1}\right)$. f, Aquaculture land use $\left(\mathrm{m}^{2} \mathrm{a} \mathrm{t}^{-1}\right)$. Values represent tonnes of edible weight and use mass allocation. Dot indicates the median, coloured regions show credible intervals (that is, range of values that have a 95\% (light), 80\% and 50\% (dark) probability of containing the true parameter value). Beige bands represent estimated chicken minimum to maximum range. See Supplementary Fig 10 for estimates expressed in terms of live weight. opportunities and discuss public and private policy options to realize these improvements. In doing so, these results help to identify current and future opportunities for blue foods within sustainable diets.

\section{Blue food environmental stressors}

Reducing food system GHG emissions is central to meeting global emission targets ${ }^{8}$. Fed aquaculture emissions result primarily from feeds ${ }^{22}$, while fuel use drives capture fisheries emissions ${ }^{11}$. Across assessed blue foods, farmed seaweeds and bivalves generate the lowest emissions, followed by small pelagic capture fisheries, while flatfish and crustacean fisheries produce the highest (Fig. 1). For fed aquaculture, feed production is responsible for more than $70 \%$ of emissions for most groups (Supplementary Fig. 6). Farmed bivalves and shrimp produce lower average emissions than their capture counterparts (bivalves, 1,414 versus $11,400 \mathrm{kgCO}_{2} \mathrm{e} \mathrm{t}^{-1}$ (kilograms of $\mathrm{CO}_{2}$ equivalent per tonne); shrimps, 9,428 versus $11,956 \mathrm{kgCO}_{2} \mathrm{e}^{-1}$ ), while salmon/trout are similar whether farmed or fished $\left(5,101-5,410\right.$ versus $\left.6,881 \mathrm{kgCO}_{2} \mathrm{e} \mathrm{t}^{-1}\right)$.

Land use, especially conversion of natural areas, results in a range of context-dependent biodiversity impacts and GHG emissions ${ }^{23}$ and creates potential trade-offs with alternate uses, including production of other foods. On-farm land use is low $\left(<1,000 \mathrm{~m}^{2}\right.$ annual terrestrial land occupation per tonne, $\mathrm{m}^{2} \mathrm{a} \mathrm{t}^{-1} ;<10 \%$ ) for most systems and highest $\left(3,737-8,689 \mathrm{~m}^{2} \mathrm{a} \mathrm{t}^{-1}\right)$ for extensive ponds (for example, milkfish, shrimp and silver and bighead carp). Generally, most land use is associated with feed production for fed systems and explains the overall rankings (Fig. 1), though milkfish uses the highest amount of on- and off-farm land.

Freshwater increasingly constrains agriculture production but capture fisheries and unfed mariculture require little to no freshwater ${ }^{24}$. Although blue foods are produced in water, consumptive freshwater use is largely limited to feed production and on-farm evaporative losses for freshwater production ${ }^{16}$, with feeds accounting for essentially all water use for marine species, but on-farm evaporative losses accounting for over $60 \%$ of water use for freshwater species. (Supplementary Fig. 6). High evaporative losses cause silver and bighead carps to have the highest total water use, 2.6 times the water use of other carps and 4.4 times the water use of catfish, while milkfish and miscellaneous marine and diadromous fishes have the highest feed-associated water use. Among fed aquaculture, trout and salmon have the lowest water use, in part attributable to lower crop utilization, highlighting a trade-off with fishmeal and fish oil.

Nitrogen and phosphorus emissions are responsible for marine and freshwater eutrophication and are highly correlated due to natural biomass N:P ratios (Supplementary Table 4). For fed systems, the majority of $\mathrm{N}(>87 \%)$ and $\mathrm{P}(>94 \%)$ emissions occur on-farm. The highest total $\mathrm{N}$ and $\mathrm{P}$ emissions result from miscellaneous farmed marine and diadromous fishes, milkfish and fed carp. Non-fed groups such as seaweeds and bivalves, as well as unfed and unfertilized finfish systems (for example, some silver and bighead carp), represent extractive systems that remove more $\mathrm{N}$ and $\mathrm{P}$ than is emitted during production, resulting in negative emissions (Fig. 1).

Across all blue foods, farmed seaweeds and bivalves generate the lowest stressors. However, these groups also highlight several assumptions and nuances. First, bivalve estimates change by nearly five-fold when expressed in terms of edible portion (Fig. 1) compared to live weight (Supplementary Fig.10) due to the shell weight. Second, some processes falling outside our system boundaries represent a potentially large fraction of life cycle emissions for these groups, even if still small in absolute value in some cases. For seaweeds, a large proportion of GHG emissions can occur at the drying stage ${ }^{25}$ while for bivalves, $\mathrm{CO}_{2}$ emissions during shell formation ${ }^{26}$ and high emissions associated with live product from transport ${ }^{27}$ can be important. Third, impacts on biogeochemical cycling and habitats are highly context dependent. For example, the systems represented here extract nitrogen and phosphorus, which could be problematic in nutrient-poor environments. Additionally, ozone effects from volatile short-lived substances depend on the location and varies widely across species ${ }^{28,29}$. Fourth, sustainable diet recommendations based on these or similar results must account for differences in nutrition content and bioavailability, a particularly important consideration for seaweeds ${ }^{30}$. Finally, these systems are underrepresented in the literature, particularly for edible seaweeds (Supplementary Fig. 3). As recommendations point towards the potential of these groups, it is 


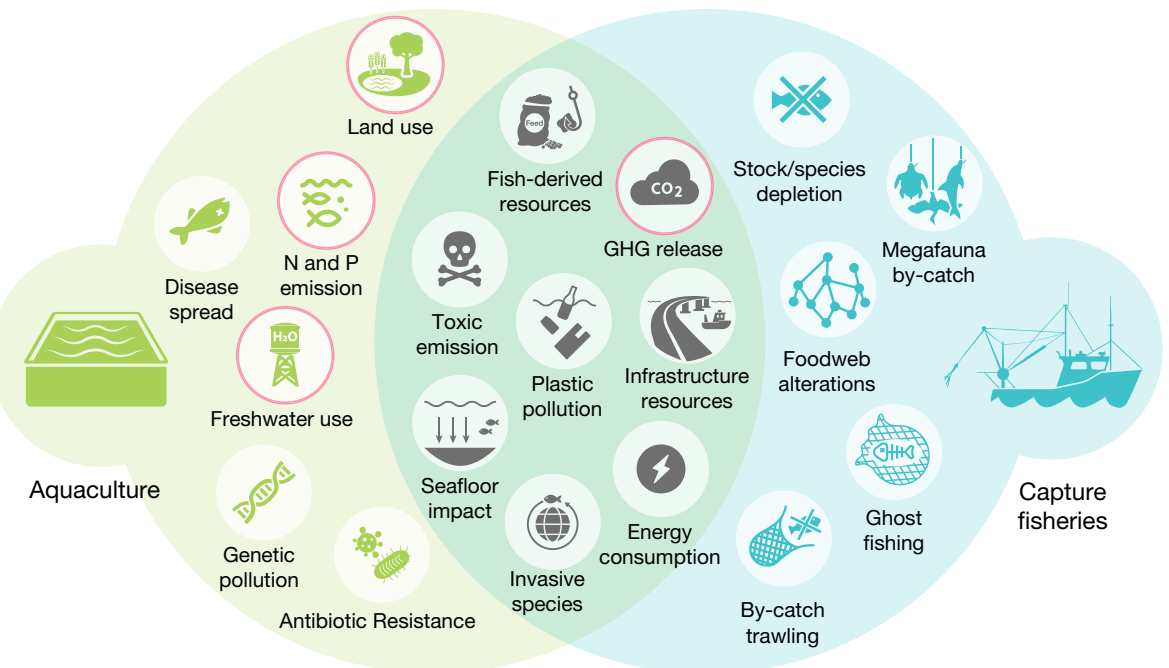

Fig. 2 | Major stressors stemming from aquaculture and capture fisheries. Icons with magenta border are quantified in this study while the others are discussed qualitatively.

important to increase data on these systems, deepen understanding of the above nuances, and be mindful of the total impacts associated with large-scale production on coastal habitats.

Capture fisheries, with negligible land, water, $\mathrm{N}$ and $\mathrm{P}$ values, also compare favourably, though groups fall at both the bottom and top of GHG rankings. Among farmed finfish and crustaceans, silver and bighead carps result in the lowest GHG, $N$ and $P$ emissions, while salmon and trout use the least land and water. To compare with terrestrial foods, we estimated stressors for industrial chicken produced in the USA and Europe and find it falls in the middle of farmed blue foods, with similar stressors as tilapia (Fig. 1, Supplementary Fig. 14). Because chicken typically has lower stressors than other livestock ${ }^{3}$, it follows that many blue food groups compare favourably to other animal-sourced foods. Notably, groups generating among the lowest stressors (for example, bivalves and small pelagic fishes) also provide the greatest nutritional quality across all forms of aquatic foods $\mathrm{s}^{2,10}$.

Our results represent the most comprehensive and standardized blue food stressor estimates to date. Overall, data availability is correlated with global aquaculture production across these taxa groups, but there are still notable taxonomic and geographic gaps (Supplementary Figs. 3, 4). Critically, there are substantial data gaps for silver and bighead carp and seaweeds given their level of production (Supplementary Fig. 3). Furthermore, our capture fishery data primarily represents commercial marine fisheries ${ }^{31}$. However, subsistence marine and inland catches often utilize non-motorized or no vessels, which probably generate few emissions, but there is insufficient data on fuel use across the diversity of small-scale fishing methods to reliably estimate emissions. These systems should be prioritized for additional research. Our estimates represent a snapshot of the knowledge of current production, but future work on emerging production technologies, feed innovations and growing sub-sectors is important for tracking changes against these benchmarks.

\section{From stressors to ecosystem impacts}

Emission and resource-use stressors are valuable for comparing environmental performance across foods but cannot fully capture final ecosystem and biodiversity consequences (that is, impacts). Estimating impacts stemming from blue food production requires considering additional stressors and accounting for local context.

While GHG, N, P, land and water are important stressors commonly used to compare foods, other less studied stressors can be critical drivers of ecosystem impacts (Fig. 2). Both aquaculture and fisheries may impose other stressors through toxic substance applications (for example, antifouling and pesticides in agriculture) and physical disturbance (for example, bottom trawling and on-bottom culture). Additional stressors include genetic pollution, invasive species introductions $^{32}$, application of antibiotics ${ }^{33}$, and disease spread ${ }^{34}$. While capture fisheries have negligible N, P, water and land stressors, other stressors can markedly alter ecosystems. Fisheries often shift size structure and abundance of targeted species (see, for example, refs. ${ }^{35,36}$ ), alter the structure of food webs (see, for example, ref. ${ }^{37}$ ) and impact non-targeted fauna through bycatch ${ }^{38}$.

Local context, such as ecosystem function, carrying/assimilating capacity, and species composition influence how stressors translate into environmental impacts ${ }^{39,40}$. Notably, land use impacts on biodiversity depend on the land use history and ecological context ${ }^{41}$. While all land used for food cultivation represents habitats converted at one point, avoiding additional agricultural expansion is important for preventing further habitat loss ${ }^{42}$. This is also true for on-farm land use by aquaculture, where conversion of ecologically valuable ecosystems, such as mangrove forest ${ }^{23}$ that serve as critical carbon $\operatorname{sinks}{ }^{43}$ and nursery habitats, can generate severe impacts. Local species composition and management contexts are also important, including risks associated with marine mammal bycatch (Box1). Individual stressors may also have nonlinear relationships with impacts or act interactively ${ }^{44,45}$, such as climate change impacts compounding land use patterns that limit climate refuges or migration options ${ }^{46}$, or resulting in more frequent disease outbreaks, that increase antibiotic use and risk of antibiotic resistance.

Capturing the full suite of environmental impacts will require more systematic data collection and methodological advancements. This is crucial for informing policy decisions and realizing the potential contributions of blue foods to sustainable diets while avoiding undesirable trade-offs. Combining local ecological risk and stressor estimates can reveal these important trade-offs, as well as potential synergies (Box1). While there are no impact-free foods, highlighting synergies simplifies sustainability messaging and helps identify priority interventions.

\section{Levers for reducing environmental impacts}

Variance in stressors indicates diversity across fishing/farming systems (Supplementary Figs. 7-9) as well as potential 'performance gaps'. High variability in milkfish and miscellaneous marine and diadromous fish 


\section{Box 1}

\section{Emissions and biodiversity risk}

Stressors from life cycle assessments quantify fishery emissions but fail to capture local ecological risks. Combining stressors and impact assessments can illuminate potential sustainability trade-offs. Ecological risk assessments have been developed for capture fisheries to promote holistic assessment of local ecological risks. Integrating GHG emissions with marine mammal risk assessments reveals that some low-GHG emission gears are associated with higher marine mammal risks (for example, gillnets and entangling nets; Fig. 3), while bottom trawls show the opposite. Acknowledging ecological context is critical because risk from similar gears varies across regions. For example, traps and lift nets generally pose low risk to marine mammals (Fig. 3). However, North Atlantic right whales (Eubalaena glacialis) in the northwest Atlantic are at high risk from entanglements in American lobster (Homarus americanus) $\operatorname{traps}^{70}$.

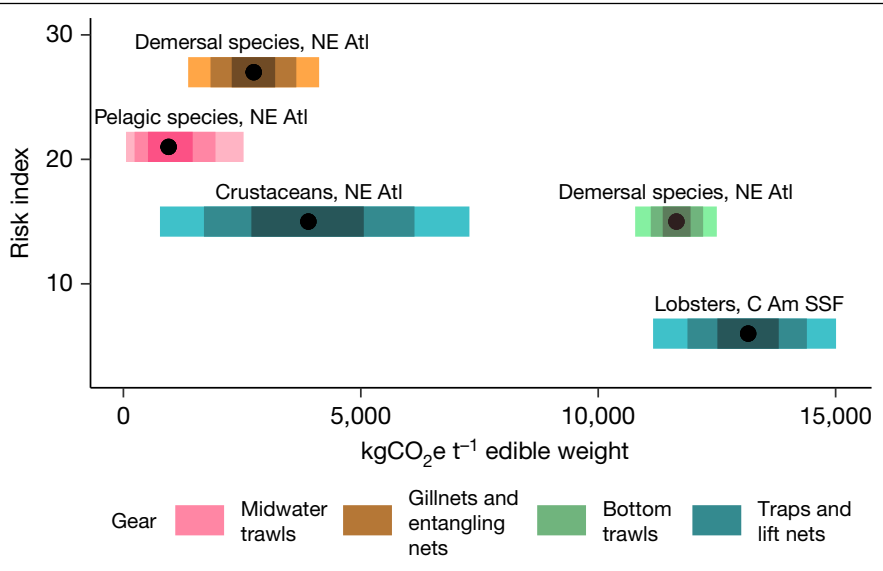

Fig. 3 | GHG emissions compared to marine mammal risk. Data represent fisheries in Europe (NE Atl) and Central America (C Am SSF) by gear type. Dot indicates the median estimate of the mean $\mathrm{kgCO}_{2} \mathrm{e} \mathrm{t}^{-1}$ and intervals show $95 \%$ (light), $80 \%$ and $50 \%$ (dark) credible intervals. Risk index is the sum of the number of marine mammals at risk times 3, 2 or 1 for high, medium or low risk, respectively.

GHG emissions. Alternatively, we find that prioritizing low-fuel gears within each fishery can reduce GHG emissions by $4-61 \%$, depending on the species (Supplementary Fig. 16). In some cases, this could create co-benefits for biodiversity impacts (Box 1). Another strategy is to transition fishing fleets to low-emission technologies ${ }^{8}$. While some fleets have transitioned to electric, hydrogen fuel and sail-assisted vessels, general adoption necessitates transformations beyond traditional fishery management.

be considerable (see, for example, ref. ${ }^{49}$ ).

We find feed conversion ratios (FCRs) represent the strongest lever, wherein a $10 \%$ reduction results in a $1-24 \%$ decrease in all stressors (Fig. 4a). To evaluate potential shifts under current technology, we estimate the effect of moving each species to the 20th percentile FCR and find the largest reductions for silver and bighead carps (Fig. 4b). However, lower FCRs generally come at the cost of larger pond $\operatorname{area}^{33}$, suggesting a potential trade-off with land and water use.

Holding all else constant, a $10 \%$ fish production yield improvement $\left(\mathrm{t} \mathrm{ha}^{-1}\right)$ reduces land and water use for freshwater pond systems by 1-10\% (Fig. 4a). Increasing yields to the 80th percentile reduces land and water use by up to $50 \%$ (Fig. 4b). Intensifying production, however, can require more energy for aeration and water pumping as well as increased disease risks with higher animal densities.

Feed composition represents another potential lever. Overall, shifting relative proportions of crop- and fish-derived inputs to feeds results in negligible changes in stressors (Fig. 4a). Comparing changes in feed sourcing, we found switching to deforestation-free soy and crops reduced GHG emissions by 5-50\% (Fig. 4b). This could create a co-benefit of also reducing biodiversity impacts. However, as part of integrated global commodity markets, reductions by aquaculture producers will only help to meet emissions targets if broader food sector commitments are made. Replacing fish meal and fish oil with fishery by-products has a relatively small effect (Fig. 4b), but increased by-product utilization can improve system-wide performance when it directs potential wastes toward more favourable applications ${ }^{50}$. Finally, novel aquaculture feeds, including algal, microorganism and insect meals, are increasingly available but currently account for a small fraction of feeds. While they are likely to hold potential to improve feed quality and reduce forage fish demand ${ }^{51}$, their impacts at scale remain uncertain $^{52}$ and therefore could not be modelled here.

For capture fisheries, reducing fuel use represents the primary stressor improvement opportunity. Increasing stock biomass could reduce fuel use per tonne of fish landed ${ }^{12,53}$, where a $13 \%$ catch increase with $56 \%$ of the effort ${ }^{54}$ corresponds to a $50 \%$ reduction in

\section{Realizing blue food's environmental potential}

Blue foods already have great potential for reducing food system environmental stressors. Unfed aquaculture results in negligible values for most considered stressors, and many fed aquaculture groups outperform industrial chicken, the most efficient major terrestrial animal-source food. Capture fisheries vary widely in their GHG emissions but are low impact with respect to the other stressors considered. This underscores the value of sustainably managing wild fisheries to avoid the environmental replacement cost that would be incurred under fish catch declines ${ }^{24}$.

Our standardized estimates enhance the resolution of the potential role of blue foods within sustainable diets, highlighting opportunities to shift demand from relatively high- to low-stressor blue foods and from terrestrial animal-source foods to comparatively low-stressor blue foods. Shifting to non-animal alternatives remains an efficient lever but low-stressor blue foods may represent an appealing alternative for some consumers. Furthermore, blue foods provide the highest nutrient richness across multiple micronutrients (for example, iron and zinc), vitamins (for example, B12), and long-chain polyunsaturated fatty acids (for example, EPA and DHA) relative to terrestrial animal-source foods ${ }^{10}$, which may provide greater incentive to shift demand as consumers generally prioritize seafood freshness, food safety, health and taste over sustainability ${ }^{55}$.

Major challenges remain for shifting demand, as well as meeting increased demand. While improved management offers potential opportunities for expanding some production from low-stressor capture fisheries, uncertainty remains around the extent and feasibility of rebuilding many fisheries ${ }^{47}$. Additional research is needed to understand the total environmental impacts of large-scale expansion of low per unit stressor foods, especially for system-specific impacts (Box1). Increasing production also requires creating appropriate incentives and reducing barriers for producers. Historical food system transitions 


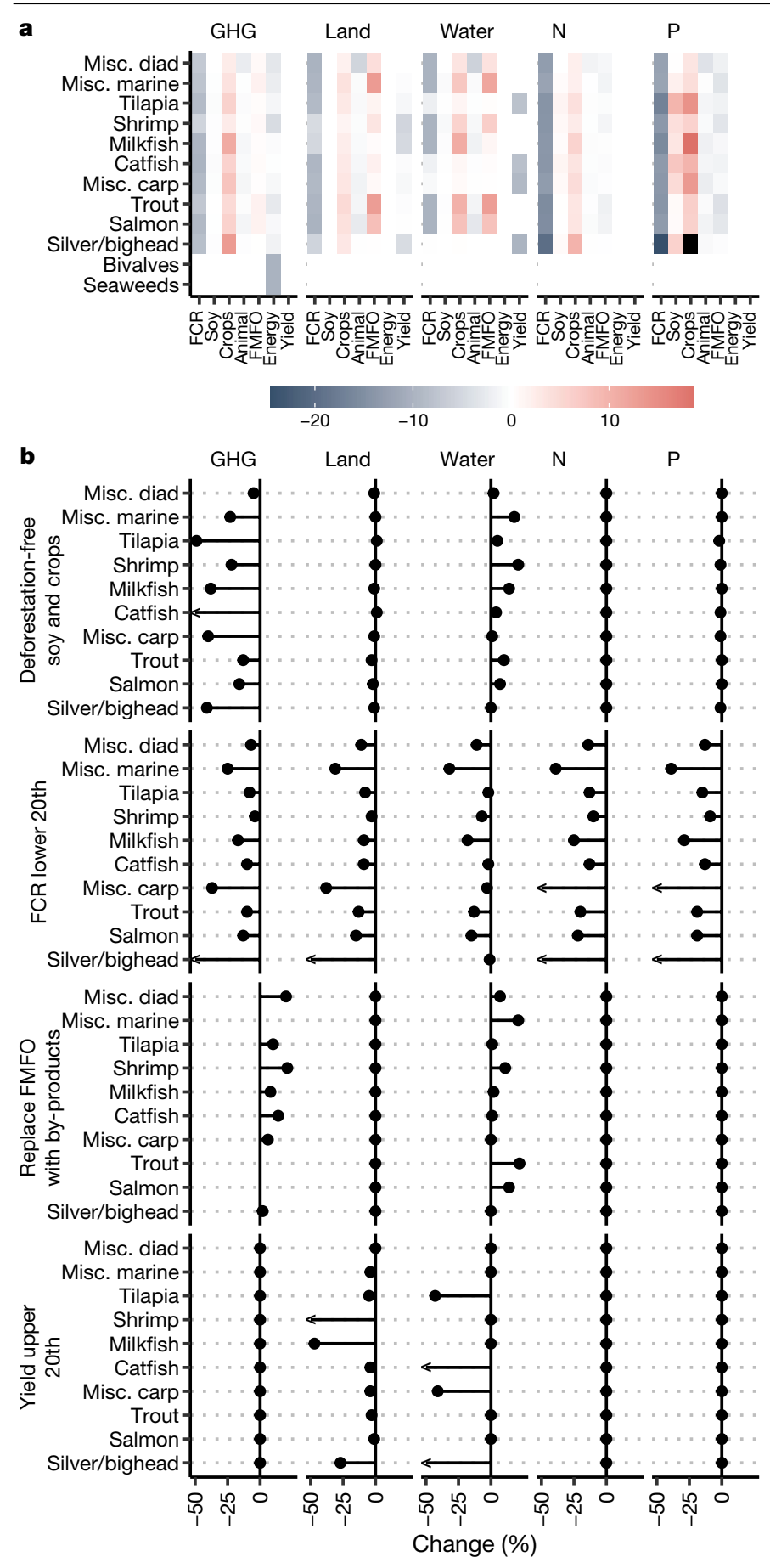

Fig. 4 | Aquaculture stressor intervention opportunities. a, Change (\%) in each stressor associate with a $10 \%$ reduction in the parameter value (black cell indicates stressor change $>20 \%$ ). b. Change (\%) in each stressor under four scenarios (defined in Supplementary Table 8) relative to the current estimate. Arrows indicate changes greater than $50 \%$. Additional aquaculture scenario results displayed in Supplementary Fig. 15 and capture scenario results in Supplementary Fig. 16 .

required public investment technologies that could be scaled up by the private sector and public policy leadership ${ }^{56}$. Overly strict regulations or lack of capital can prevent expansion of low-stressor blue foods such as offshore mussel farms (see, for example, ref. ${ }^{57}$ ). Facilitating low-stressor blue food expansion and novel production methods may require new and more adaptive policies and distribution of grants or other forms of start-up capital. Finally, policies can steer production and consumption through taxes and subsidies ${ }^{58}$ as well as softer policies, such as dietary advice that considers environmental impacts ${ }^{59}$.

Within the diversity of blue food production there are numerous opportunities to reduce environmental stressors. As a young and rapidly growing sector, there are many promising technological innovations in aquaculture (for example, recirculating aquaculture systems, offshore farming and novel feeds). However, less charismatic interventions may represent greater potential for rapid and substantial impact reductions. These include policy or technological interventions that improve husbandry measures (especially reducing disease and mortality) and lower FCRs. Improved management in salmon aquaculture demonstrated considerable sustainability benefits through disease and area management plans ${ }^{60}$ and improved stock management with precision aquaculture and automation ${ }^{61}$. Furthermore, selective breeding, genetic improvements and high-quality feeds can all reduce FCRs (Supplementary Table 8). While we looked at individual interventions, improvements are likely to occur through a suite of interventions and the synergistic or antagonistic interactions of interventions represents an important area for future work. Unfortunately, many innovations are often beyond the reach of smallholder producers of low-value species. This highlights a need for public research and development as well as technology transfer to enable all farmers to adopt practices that reduce environmental stressors. For capture fisheries, continued management reforms together with incentives to use low-fuel gears could substantially improve the performance of capture fisheries ${ }^{11,47}$. A range of actors will be important for stimulating a shift to more sustainable production methods and, for instance, nation states, civil society and the private sector all have important roles. Private sector pre-competitive collaborations; for example, SeaBOS ${ }^{62}$ and the Global Salmon Initiative can help to stimulate production improvements at scale. Likewise, government-led initiatives helping small-holders improve their farming practices through, for example, access to high quality feeds, seed and broodstock, are crucial for closing the aquaculture performance gap ${ }^{63-65}$. Certification and improvement projects can help to reduce ecosystem impacts ${ }^{66}$, but have been criticized for passive exclusion of small-scale producers. Moving towards best practices such as state-led, national certification schemes and area-based approaches will therefore be key ${ }^{67}$. Finally, the finance sector can help to steer the sector towards sustainability through strategic investments ${ }^{68}$.

The above findings do not suggest unlimited blue food growth is possible nor that expansion comes without environmental trade-offs. Furthermore, without careful consideration for local contexts and inclusion of relevant stakeholders, environmentally focused interventions can generate social and economic trade-offs that undermine broader sustainability goals. Nevertheless, farmed blue food is among the fastest growing food sectors and the global community now faces a unique window of opportunity to steer expansion towards sustainability ${ }^{69}$. Our model and results provide blue food stressor benchmarks and enable data-poor environmental stressor assessments. This serves as a critical foundation for understanding blue food environmental performance and to ensuring sustainable and healthy blue foods are available now and into the future.

\section{Online content}

Any methods, additional references, Nature Research reporting summaries, source data, extended data, supplementary information, acknowledgements, peer review information; details of author contributions and competing interests; and statements of data and code availability are available at https://doi.org/10.1038/s41586-021-03889-2.

1. Gephart, J. A. et al. The environmental cost of subsistence: optimizing diets to minimize footprints. Sci. Total Environ. 553, 120-127 (2016).

2. Hallström, E. et al. Combined climate and nutritional performance of seafoods. J. Clean. Prod. 230, 402-411 (2019). 
3. Poore, J. \& Nemecek, T. Reducing food's environmental impacts through producers and consumers. Science 360, 987-992 (2018).

4. Halpern, B. S. et al. Opinion: Putting all foods on the same table: achieving sustainable food systems requires full accounting. Proc. Natl Acad. Sci. USA 116, 18152-18156 (2019).

5. The State of World Fisheries and Aquaculture (SOFIA) (FAO, 2O20).

6. The State of the World's Land and Water Resources for Food and Agriculture (SOLAW): Managing Systems at Risk (FAO, 2011).

7. Food Security and Nutrition: Building a Global Narrative Towards 2030 (HLPE, 2020).

8. Willett, W. et al. Food in the Anthropocene: the EAT-Lancet Commission on healthy diets from sustainable food systems. Lancet 393, 447-492 (2019).

9. Micha, R. et al. 2020 Global Nutrition Report: Action on Equity to End Malnutrition (Global Nutrition Report, 2020).

10. Golden, C. D. Aquatic foods to nourish nations. Nature (in the press)

11. Parker, R. W. R. et al. Fuel use and greenhouse gas emissions of world fisheries. Nat. Clim. Change 8, 333-337 (2018)

12. Hoegh-Guldberg, O. et al. The Ocean as a Solution to Climate Change: Five Opportunities for Action (Ocean Panel, 2019).

13. Farmery, A. K., Gardner, C., Jennings, S., Green, B. S. \& Watson, R. A. Assessing the inclusion of seafood in the sustainable diet literature. Fish Fish. 18, 607-618 (2017)

14. MacLeod, M. J., Hasan, M. R., Robb, D. H. F. \& Mamun-Ur-Rashid, M. Quantifying greenhouse gas emissions from global aquaculture. Sci. Rep. 10, 11679 (2020)

15. Hilborn, R., Banobi, J., Hall, S. J., Pucylowski, T. \& Walsworth, T. E. The environmental cost of animal source foods. Front. Ecol. Environ. 16, 329-335 (2018).

16. Gephart, J. A. et al. The 'seafood gap' in the food-water nexus literature-issues surrounding freshwater use in seafood production chains. Adv. Water Resour. 110, 505-514 (2017).

17. Tilman, D. \& Clark, M. Global diets link environmental sustainability and human health. Nature 515, 518-522 (2014).

18. Springmann, M. et al. Options for keeping the food system within environmental limits. Nature 562, 519-525 (2018)

19. Reap, J., Roman, F., Duncan, S. \& Bras, B. A survey of unresolved problems in life cycle assessment: Part 2: impact assessment and interpretation. Int. J. Life Cycle Assess. 13 374-388 (2008)

20. Henriksson, P. J. G. et al. A rapid review of meta-analyses and systematic reviews of environmental footprints of food commodities and diets. Glob. Food Secur. 28, 100508 (2021).

21. Naylor, R. L. et al. Blue food demand across geographic and temporal scales. Nature (in the press).

22. Henriksson, P. J. G., Pelletier, N. L., Troell, M. \& Tyedmers, P. Life cycle assessment and its application to aquaculture production systems. In Encyclopedia of Sustainability Science and Technology (ed. Meyers, R.) (Springer, 2012).

23. Richards, D. R., Thompson, B. S. \& Wijedasa, L. Quantifying net loss of global mangrove carbon stocks from 20 years of land cover change. Nat. Commun. 11, 4260 (2020)

24. Gephart, J. A., Pace, M. L. \& D'Odorico, P. Freshwater savings from marine protein consumption. Environ. Res. Lett. 9, 014005 (2014).

25. van Oirschot, R. et al. Explorative environmental life cycle assessment for system design of seaweed cultivation and drying. Algal Res. 27, 43-54 (2017).

26. Ray, N. E., O'Meara, T., Wiliamson, T., Izursa, J.-L. \& Kangas, P. C. Consideration of carbon dioxide release during shell production in LCA of bivalves. Int. J. Life Cycle Assess. 23 1042-1048 (2018).

27. Iribarren, D., Moreira, M. T. \& Feijoo, G. Revisiting the life cycle assessment of mussels from a sectorial perspective. J. Clean. Prod. 18, 101-111 (2010).

28. Tegtmeier, S. et al. Emission and transport of bromocarbons: from the West Pacific ocean into the stratosphere. Atmospheric Chem. Phys. 12, 10633-10648 (2012).

29. King, G. M. Aspects of carbon monoxide production and oxidation by marine macroalgae. Mar. Ecol. Prog. Ser. 224, 69-75 (2001).

30. Flores, S. R. L., Dobbs, J. \& Dunn, M. A. Mineral nutrient content and iron bioavailability in common and Hawaiian seaweeds assessed by an in vitro digestion/Caco-2 cell model. J. Food Compos. Anal. 43, 185-193 (2015).

31. Parker, R. W. R. \& Tyedmers, P. H. Fuel consumption of global fishing fleets: current understanding and knowledge gaps. Fish Fish. 16, 684-696 (2015).

32. Molnar, J. L., Gamboa, R. L., Revenga, C. \& Spalding, M. D. Assessing the global threat of invasive species to marine biodiversity. Front. Ecol. Environ. 6, 485-492 (2008).

33. Henriksson, P. J. G. et al. Unpacking factors influencing antimicrobial use in global aquaculture and their implication for management: a review from a systems perspective. Sustain. Sci. 13, 1105-1120 (2018)

34. Murray, A. G. Epidemiology of the spread of viral diseases under aquaculture. Curr. Opin. Virol. 3, 74-78 (2013)

35. Myers, R. A. \& Worm, B. Rapid worldwide depletion of predatory fish communities. Nature 423, 280-283 (2003)

36. Svedäng, H. \& Hornborg, S. Selective fishing induces density-dependent growth. Nat. Commun. 5, 4152 (2014).

37. Howarth, L. M., Roberts, C. M., Thurstan, R. H. \& Stewart, B. D. The unintended consequences of simplifying the sea: making the case for complexity. Fish Fish. 15, 690-711 (2014)

38. Roda, M. A. P. et al. A Third Assessment of Global Marine Fisheries Discards (FAO, 2019).
39. Halpern, B. S., Selkoe, K. A., Micheli, F. \& Kappel, C. V. Evaluating and ranking the vulnerability of global marine ecosystems to anthropogenic threats. Conserv. Biol. 21, 1301-1315 (2007).

40. Weitzman, J. \& Filgueira, R. The evolution and application of carrying capacity in aquaculture: towards a research agenda. Rev. Aquac. 12, 1297-1322 (2019).

41. Martin, D. A. et al. Land-use history determines ecosystem services and conservation value in tropical agroforestry. Conserv. Lett. 13, e12740 (2020).

42. Williams, D. R. et al. Proactive conservation to prevent habitat losses to agricultural expansion. Nat. Sustain. 4, 314-322 (2021).

43. Mcleod, E. et al. A blueprint for blue carbon: toward an improved understanding of the role of vegetated coastal habitats in sequestering $\mathrm{CO}_{2}$. Front. Ecol. Environ. 9, 552-560 (2011).

44. Selkoe, K. A. et al. Principles for managing marine ecosystems prone to tipping points. Ecosyst. Health Sustain. 1, 1-18 (2015).

45. Crain, C. M., Kroeker, K. \& Halpern, B. S. Interactive and cumulative effects of multiple human stressors in marine systems. Ecol. Lett. 11, 1304-1315 (2008)

46. Guo, F., Lenoir, J. \& Bonebrake, T. C. Land-use change interacts with climate to determine elevational species redistribution. Nat. Commun. 9, 1315 (2018).

47. Costello, C., Cao, L. \& Gelcich, S. The Future of Food from the Sea (Ocean Panel, 2019).

48. Bohnes, F. A., Hauschild, M. Z., Schlundt, J. \& Laurent, A. Life cycle assessments of aquaculture systems: a critical review of reported findings with recommendations for policy and system development. Rev. Aquac. 11, 1061-1079 (2019).

49. Bergman, K. et al. Recirculating aquaculture is possible without major energy tradeoff life cycle assessment of warmwater fish farming in Sweden. Environ. Sci. Technol. 54 16062-16070 (2020).

50. Stevens, J. R., Newton, R. W., Tlusty, M. \& Little, D. C. The rise of aquaculture by-products: increasing food production, value, and sustainability through strategic utilisation. Mar. Policy 90, 115-124 (2018).

51. Cottrell, R. S., Blanchard, J. L., Halpern, B. S., Metian, M. \& Froehlich, H. E. Global adoption of novel aquaculture feeds could substantially reduce forage fish demand by 2030 . Nat. Food 1, 301-308 (2020)

52. Pelletier, N., Klinger, D. H., Sims, N. A., Yoshioka, J.-R. \& Kittinger, J. N. Nutritional attributes, substitutability, scalability, and environmental intensity of an illustrative subset of current and future protein sources for aquaculture feeds: joint consideration of potential synergies and trade-offs. Environ. Sci. Technol. 52, 5532-5544 (2018).

53. Hornborg, S. \& Smith, A. D. M. Fisheries for the future: greenhouse gas emission consequences of different fishery reference points. ICES J. Mar. Sci. 77, 1666-1671 (2020).

54. The Sunken Billions Revisited: Progress and Challenges in Global Marine Fisheries. (World Bank, 2017).

55. Understanding seafood consumers. MSC https://www.msc.org/understanding-seafoodconsumers (2021).

56. Moberg, E. et al. Combined innovations in public policy, the private sector and culture can drive sustainability transitions in food systems. Nat. Food 2, 282-290 (2021).

57. Fairbanks, L. Moving mussels offshore? Perceptions of offshore aquaculture policy and expansion in New England. Ocean Coast. Manag. 130, 1-12 (2016).

58. Säll, S. \& Gren, I.-M. Effects of an environmental tax on meat and dairy consumption in Sweden. Food Pol. 55, 41-53 (2015).

59. Fischer, C. G. \& Garnett, T. Plates, Pyramids, Planet: Developments in National Healthy and Sustainable Dietary Guidelines: A State of Play Assessment (FAO, 2016).

60. Jones, S., Bruno, D., Madsen, L. \& Peeler, E. Disease management mitigates risk of pathogen transmission from maricultured salmonids. Aquac. Environ. Interact. 6, 119-134 (2015).

61. Antonucci, F. \& Costa, C. Precision aquaculture: a short review on engineering innovations. Aquac. Int. 28, 41-57 (2020).

62. Österblom, H., Jouffray, J.-B., Folke, C. \& Rockström, J. Emergence of a global sciencebusiness initiative for ocean stewardship. Proc. Natl Acad. Sci. USA 114, 9038-9043 (2017).

63. Watson, J. R., Armerin, F., Klinger, D. H. \& Belton, B. Resilience through risk management: cooperative insurance in small-holder aquaculture systems. Heliyon 4, e00799 (2018).

64. Hasan, M. R. On-farm Feeding and Feed Management in Aquaculture (FAO, 2010).

65. Bondad-Reantaso, M. G. Assessment of Freshwater Fish Seed Resources for Sustainable Aquaculture (FAO, 2007).

66. Gutiérrez, N. L. et al. Eco-label conveys reliable information on fish stock health to seafood consumers. PLoS ONE 7, e43765 (2012)

67. Bush, S. R. et al. Inclusive environmental performance through 'beyond-farm' aquaculture governance. Curr. Opin. Environ. Sustain. 41, 49-55 (2019).

68. Jouffray, J.-B., Crona, B., Wassénius, E., Bebbington, J. \& Scholtens, B. Leverage points in the financial sector for seafood sustainability. Sci. Adv. 5, eaax3324 (2019).

69. Gephart, J. A. et al. Scenarios for global aquaculture and its role in human nutrition. Rev. Fish. Sci. Aquac. 29, 122-138 (2021).

70. Myers, H. J. \& Moore, M. J. Reducing effort in the U.S. American lobster (Homarus americanus) fishery to prevent North Atlantic right whale (Eubalaena glacialis) entanglements may support higher profits and long-term sustainability. Mar. Policy 118, 104017 (2020).

Publisher's note Springer Nature remains neutral with regard to jurisdictional claims in published maps and institutional affiliations.

(c) The Author(s), under exclusive licence to Springer Nature Limited 2021 


\section{Article}

\section{Data availability}

All data used to produce the results of our analysis are available in the Supplementary Information and on GitHub (https://github.com/ jagephart/FishPrint), with the published version archived (https://doi. org/10.5281/zenodo.5338614). Source data are provided with this paper.

\section{Code availability}

All code used to produce the results of our analysis are available in the Supplementary Information and on GitHub (https://github.com/ jagephart/FishPrint), with the published version archived (https:// doi.org/10.5281/zenodo.5338614). Source data are provided with this paper.

Acknowledgements This paper is part of the Blue Food Assessment (https://www.bluefood. earth/), a comprehensive examination of the role of aquatic foods in building healthy, sustainable and equitable food systems. The assessment was supported by the Builders Initiative, the MAVA Foundation, the Oak Foundation, and the Walton Family Foundation, and has benefitted from the intellectual input of the wider group of scientists leading other components of the Blue Food Assessment work. J.A.G., K.D.G. and C.D.G. were supported by funding under NSF 1826668. A.S. was supported by a grant from the Nature Conservancy. P.H. undertook this work as part of the CGIAR Research Programs on Fish Agri-Food Systems (FISH) led by WorldFish and on Climate Change, Agriculture and Food Security (CCAFS) led by CIAT.P.H. and A.S. were partially supported by FORMAS Inequality and the Biosphere project (2020-00454).Funding for participation of S.H., K.B.; M.T., P.H. and F.Z. came from Swedish Research Council Formas (grants 2016-00227 and 2017-00842). This work was financially supported, in part, by the Harvard Data Science Initiative. We thank Fernando Cagua for his review of the model code.

Author contributions J.A.G., P.J.G.H., R.P. and A.S. contributed equally to the study. J.A.G. and C.G. organized the initial workshop. J.A.G., P.J.G.H., R.P., A.S., G.E., C.D.G., P.T. and M.T. conceived the idea and designed the overall study. J.A.G., P.J.G.H., R.P., A.S., K.D.G., S.H., K.M., M.M., R.N. W.Z. and F.Z. compiled the data. J.A.G. and K.D.G. developed the model and analysed the data All authors reviewed the results and contributed to and approved the final manuscript.

Competing interests The authors declare the following competing interests: R.W.R.P. became employed by the Aquaculture Stewardship Council while this manuscript was under consideration.

Additional information

Supplementary information The online version contains supplementary material available at https://doi.org/10.1038/s41586-021-03889-2.

Correspondence and requests for materials should be addressed to Jessica A. Gephart. Peer review information Nature thanks Michael Clark, Alexis Laurent and the other, anonymous, reviewer(s) for their contribution to the peer review of this work. Peer reviewer reports are available.

Reprints and permissions information is available at http://www.nature.com/reprints. 